\title{
The Human Genome Project
}

Trisha Greenhalgh

$J$ R Soc Med 2005;98:545

On 14 April 2003 the US Human Genome Research Institute announced that scientists had just clipped into place the very last piece in the colossal jigsaw of human DNA. The next day's newspapers reminded us that, whilst it was early days yet, a host of diseases from eczema to dementia could one day be history.

'One of our projects', said the Director of the Institute at the time, 'is to identify genes that predispose to type II diabetes. This disease affects about 1 in 20 people over 45 and its incidence appears to be increasing. Using freely available map and sequence information [we] have been able to close in on the likely gene on chromosome 20 that is altered in type II diabetes.'

And then what? Develop a drug that blocks its expression? Test the entire population and announce the unlucky one in 20 so that insurance companies can blacklist them? Tell them not to marry anyone with the same 'defect'?

It is not entirely a male thing, but the Human Genome Project has always struck me as an extension of the fantasies my three brothers used to have over their Meccano sets. Take the genome to bits and lay it out on the table. Find out the bit that is wonky and fix it. Build it up again. And so on.

Of course, thousands of people already owe their lives directly to information produced as part of the Human Genome Project. But millions more have pinned their hopes on a technical-fix solution for diseases whose origins are more meaningfully explained at the level of environment and lifestyle than that of the genome. That is not to say that there is no gene for type II diabetes on chromosome 20. But as the scientists involved know perfectly well, diabetes is polygenically determined and depends for its phenotypic expression on an obesogenic environment for which effective interventions (such as legal restrictions on the composition and portion size of fast food) are available but not politically acceptable. ${ }^{1}$

Professor of Primary Health Care, University College London, UK

E-mail: p.greenhalgh@pcps.ucl.ac.uk
Professor Haridimos Tsoukas, in an article called 'The tyanny of light' published when the Human Genome Project had scarcely begun, argues that the so-called information society, in which a wealth of information is immediately and freely available, appears to liberate us from the shackles of ignorance and create a better world based on more certain and complete knowledge. But in reality the information society spawns paradoxes that prevent it from satisfying the temptations it creates. The more information we have, the more what-ifs and ah-buts must be factored in. The more information we have, the longer we spend processing it instead of taking action. And the more information we have, the less we trust it. ${ }^{2}$

If Tsoukas (who was not talking specifically about genetics) is right, then the illumination that we anticipate will emerge from the Human Genome Project by the generation and cross-linking of 2.9 billion units of abstracted and decontextualized information on the world's five billion inhabitants will not only never materialize, but things will get darker, not lighter, as more information accrues. The sheer volume of information, warns Tsoukas, will become unfathomable as well as unmanageable.

Sequencing the human genome was a good idea, and much good will come of it. But diabetes, to choose one example, is a disease about which we are already able to give good-enough preventive health advice and take goodenough public health action to save millions of lives worldwide. If we are to realize the promise of the Human Genome Project, we must disabuse the public-and ourselves - of the notion that whatever the medical question, genetic information will provide the answer, and we must refocus the activity of geneticists on the minority of diseases for which the appropriate unit of analysis is the base pair.

\section{REFERENCES}

1 Egger G, Swinburn B. An "ecological" approach to the obesity pandemic. BMJ 1977;315:477-80

2 Tsoukas H. The tyranny of light: the temptations and paradoxes of the information society. Futures 1997;29:827-43 